\title{
PENGARUH METODE EKSTRAKSI TERHADAP MUTU PEKTIN DARI KULIT PISANG RAJA NANGKA
}

\author{
Vika Ayu Devianti ${ }^{*}$, Rosita Dwi Chrisnandari ${ }^{1}$, Rizky Darmawan ${ }^{1}$ \\ ${ }^{1}$ DIII Farmasi, Akademi Farmasi Surabaya \\ "email: vikaayu@akfarsurabaya.ac.id
}

Received 12 November 2019

Accepted 31 December 2019

\begin{abstract}
Abstrak
Ekstraksi dengan microwave dan pemanasan langsung merupakan metode yang dapat digunakan untuk ekstraksi pektin dari kulit pisang raja nangka. Penelitian ini bertujuan untuk mengetahui mutu pektin menggunakan metode ekstraksi dengan bantuan microwave dan pemanasan langsung. Berdasar hasil penelitian, diketahui bahwa ekstraksi pektin dengan bantuan microwave memiliki rendemen yang lebih tinggi dibandingkan metode pemanasan langsung. Ekstraksi dengan bantuan microwave menghasilkan pektin dengan kadar air lebih rendah dibandingkan ekstraksi pemanasan langsung. Berat ekivalen berkurang dengan meningkatnya daya microwave. Pektin yang diperoleh dari hasil ekstraksi pemanasan langsung dan microwave tergolong pektin bermetoksil rendah (Derajat esterifikasi < 50\%). Kesimpulan dari penelitian ini menunjukkan bahwa ekstraksi menggunakan daya $450 \mathrm{~W}$ dengan lama waktu ekstraksi lima menit merupakan kondisi ekstraksi yang terbaik untuk mengekstrak pektin dalam kulit Pisang Raja Nangka.
\end{abstract}

Kata kunci: Kulit Pisang Raja Nangka, pektin, microwave, pemanasan langsung

\begin{abstract}
Microwave-assisted extraction (MAE) and direct heating extraction are methods that can be carried out for extraction pectin from Raja Nangka Banana peels. This study aims to determine the quality of pectin using microwave-assisted extraction and direct heating extraction. The result of this study indicated that microwave-assisted extraction had higher yield of pectin than direct heating extraction method. The equivalen weight of pectin decreased with increasing microwave power. Pectin extracted from microwave-assisted extraction and direct heating extraction were classified as low methoxyl pectin (esterification degree $<50 \%$ ). The conclusion of this study showed that pectin in microwave-assisted extraction had a higher yield in a shorter time than direct heating extraction. Microwave-assisted Extraction at $450 \mathrm{~W}$ in 5 minutes extraction time was the best condition for extracting pectin from Raja Nangka Banana Peels in consequence of its capability to extract pectin with conformable yield and quality compared to direct heating extraction.
\end{abstract}

Keywords: Pectin, Raja Nangka Banana peels, microwave-assisted Extraction, Direct Heating Extraction

\section{Pendahuluan}

Pektin, yang tergolong heteropolisakarida kompleks, merupakan bahan pangan fungsional dalam industri makanan. Pektin terdapat di dalam dinding sel primer dan lamella tengah jaringan tanaman, serta berperan penting dalam

viabilitas sel tanaman (Chaharbaghi dkk., 2017). Pektin tersusun atas rantai ikatan $\alpha$, 1-4 asam galakturonat yang teresterifikasi sebagian dengan metil alkohol pada asam karboksilat. Struktur pektin mengandung asam polisakarida dan bersifat mampu 
mengikat air, sehingga dapat bersifat sebagai pengental (Bagherian dkk., 2011). Pektin komersial dapat diperoleh dari kulit buah - buahan, yang merupakan produk samping dari proses pengolahan buah buahan.

Komoditas buah unggulan di Indonesia adalah pisang. Pada tahun 2015, produksi pisang di Indonesia meningkat hingga $4,92 \%$ atau 5,91 juta ton dan diperkirakan terus meningkat hingga mencapai 6,55 juta ton pada tahun 2020. Jawa timur merupakan provinsi yang memberikan kontribusi paling tinggi yaitu $21,82 \%$ per tahun (Pusat Data dan Sistem Informasi Pertanian, 2016). Produksi pisang tersebut menghasilkan produk samping yaitu kulit pisang. Sebagian besar kulit pisang hanya dibuang sebagai limbah dan belum dimanfaatkan secara optimal. Produksi pektin dari kulit pisang diharapkan dapat meningkatkan nilai ekonominya.

Metode konvensional yang umum dilakukan untuk ekstraksi pektin adalah dengan pemanasan pada suhu $90-100{ }^{\circ} \mathrm{C}$ menggunakan pelarut asam mineral, seperti $\mathrm{HCl}$ (Chan dan Choo, 2013; Swamy dan Muthukumarappan, 2017) dan asam nitrat (Methacanon, Krongsin, and Gamonpilas 2014; Shaha, Punichelvana, and Afandi 2013) dengan lama waktu ekstraksi 1 - 3 jam (Chaharbaghi dkk., 2017; Dranca dan Oroian, 2018; Woo dkk., 2010). Asam sitrat mampu menghasilkan rendemen dan kualitas pektin yang lebih baik jika dibandingkan asam mineral yang lain (Chan dan Choo 2013; Sandarani 2017; Gazala dkk., 2017). Metode konvensional dengan pemanasan pada suhu tinggi $\left(\geq 80^{\circ} \mathrm{C}\right)$ dapat mengurangi kualitas pektin hasil ekstraksi. Metode pemanasan ini merupakan metode yang sederhana sehingga umum digunakan untuk produksi pektin.

Metode lain yang dapat digunakan untuk ekstraksi pektin adalah Microwave Assisted Extraction (MAE). MAE menggunakan prinsip pemanasan dielektrik yang melibatkan radiasi microwave (Sandarani, 2017). Microwave mampu memberikan panas yang lebih merata sehingga mampu menghasilkan rendemen pektin lebih banyak dengan konsumsi energi yang rendah dalam waktu yang relatif singkat (Rahmati dkk., 2019; Rodsamran dan Sothornvit, 2019; Swamy dan Muthukumarappan, 2017). Oleh karena itu, metode MAE ini dianggap sebagai metode yang potensial untuk ekstraksi pektin.

Pada penelitian sebelumnya membandingkan rendemen pektin dari kulit pisang yang diperoleh antara hasil ekstraksi menggunakan metode pemanasan dengan MAE (Devianti, dkk., 2019). Berdasar hasil tersebut diketahui bahwa rendemen pektin yang optimal pada metode pemanasan langsung dan MAE, masing - masing, secara berturut - turut membutuhkan waktu dua jam $(10,30 \%)$ dan 15 menit $(28,74 \%)$. Sedangkan pada penelitian ini bertujuan untuk mengetahui kualitas pektin yang diekstraksi menggunakan metode MAE. Kualitas pektin yang diamati adalah kandungan senyawa anorganik, berat ekivalen, kadar metoksil, dan derajat esterifikasi pektin.

\section{Metode Penelitian \\ Bahan Kimia}

Bahan atau Reagen kimia yang digunakan penelitian ini antara lain etanol 96\% (Fulltime, Indonesia), Asam sitrat monohidrat (Merck, Indonesia), akuades, dan kulit pisang raja nangka.

\section{Preparasi Serbuk Kulit Pisang}

Buah pisang raja nangka diperoleh dari pedagang pisang yang beredar di Pasar Wonokromo, Kota Surabaya. Kulit pisang dipisahkan dari daging buahnya dan dibersihkan menggunakan tisu. Lalu, dijemur dibawah sinar matahari selama dua hari dan dikeringkan menggunakan oven pada suhu $50{ }^{\circ} \mathrm{C}$ hingga memiliki berat konstan. Kulit pisang yang telah kering lalu diblender hingga halus dan diayak menggunakan mesh 100.

\section{Ekstraksi Pektin Menggunakan Metode} $M A E$ 
Serbuk kulit pisang raja nangka dimasukkan kedalam labu alas bundar, dan ditambahkan asam sitrat dengan konsentrasi tertentu (5, 7, dan 9\%). Rasio bahan dan pelarut yang digunakan adalah 1:50. Larutan tersebut kemudian dipanaskan dalam microwave dengan daya (300 dan $450 \mathrm{~W}$ ), lama waktu ekstraksi (15, 20, dan 25 menit), dan suhu pemanasan $\pm 70{ }^{\circ} \mathrm{C}$. Setelah proses ekstraksi selesai, larutan tersebut disaring, dan filtrat yang diperoleh didinginkan. Lalu, filtrat diendapkan dengan etanol 96\% dan didiamkan selama 24 jam. Endapan yang diperoleh dicuci dengan etanol 96\% hingga larutan filtrat yang diperoleh berubah warna menjadi tidak berwarna. Endapan ekstrak yang diperoleh dikeringkan pada suhu $40{ }^{\circ} \mathrm{C}$ selama 8 jam.

\section{Analisis Kualitatif Pektin}

Analisis kualitatif pektin dilakukan dengan langkah sebagai berikut:

a. Pektin $1 \%$ diambil $1 \mathrm{~mL}$, ditambah etanol $96 \%$ dengan volume yang sama. Hasil dikatakan positif bila terbentuk endapan bening seperti gelatin,

b. Larutan pektin $1 \%$ diambil $5 \mathrm{~mL}$, ditambah $1 \mathrm{~mL} \mathrm{NaOH} 2 \mathrm{~N}$, didiamkan pada suhu ruang selama 15 menit. Hasil positif bila terbentuk gel atau semigel,

c. Hasil pengujian (b) diasamkan dengan $\mathrm{HCl} 3 \mathrm{~N}$ dan dikocok. Hasil positif bila terbentuk endapan seperti gelatin dan bergumpal bila dididihkan (asam pektat.

\section{Analisis Kandungan Senyawa Anorganik}

Serbuk pektin hasil ekstrak kulit pisang kemudian dianalisis kandungan senyawa anorganik menggunakan menggunakan spektrofotometer X-Ray Fluorometer (XRF). Analisis kandungan senyawa anorganik ini bertujuan untuk mengetahui kemurnian pektin. Semakin tinggi kandungan senyawa anorganik, semakin rendah kemurnian pektin.

\section{Analisis Gugus Fungsi Pektin}

Spektra FTIR pektin yang telah diekstrak dari kulit pisang menggunakan metode MAE dengan daya 300 dan $450 \mathrm{~W}$ dianalisis pada bilangan gelombang 4000 hingga $500 \mathrm{~cm}^{-1}$. Gugus fungsi pektin ditampilkan pada tabel 2 dan hasil yang diperoleh dibandingkan dengan Pavia, dkk., (2009).

\section{Penentuan Berat Ekivalen}

Penentuan berat ekivalen, kadar metoksil dan galakturonat dilakukan berdasar metode yang pernah dijelaskan oleh Ismail dkk., (2012). Nilai berat ekivalen digunakan untuk menghitung asam galakturonat dan derajat esterifikasi. Berat ekivalen ditentukan dengan cara menimbang 0,1 g pektin, lalu dilembabkan dengan $1 \mathrm{~mL}$ etanol 96\%, dilarutkan dalam $20 \mathrm{~mL}$ akuades bebas $\mathrm{CO}_{2}$ pada suhu $40^{\circ} \mathrm{C}$ dan distirrer selama 1 jam untuk melarutkan pektin dan tidak ada gumpalan yang tersisa di sisi erlenmenyer. Lalu, ditambah 0,2 gram $\mathrm{NaCl}$ dan 3 tetes indikator phenolphtalein. Titrasi dilakukan secara perlahan - lahan (untuk mencegah de-esterifikasi) dengan $\mathrm{NaOH} 0,1 \mathrm{~N}$ yang telah distandarisasi hingga berubah warna menjadi merah muda (pH 7,5) selama 30 detik. Larutan netral tersebut digunakan untuk menentukan kadar metoksil. Berat ekivalen ditentukan menggunakan persamaan berikut :

$$
\text { Berat ekivalen }=\frac{\text { berat sampel }(\mathrm{g}) \times 1000}{\text { vol titran }(\mathrm{mL}) \times \mathrm{N} \text { titran }}
$$

\section{Analisis Kadar Metoksil}

Penentuan kadar metoksil dilakukan dengan cara menambahkan $10 \mathrm{~mL} \mathrm{NaOH}$ $0,25 \mathrm{~N}$ pada larutan yang telah dititrasi, distirrer selama 1 jam pada suhu ruang dalam erlenmenyer tertutup. Setelah itu, ditambah $10 \mathrm{~mL} \mathrm{HCl} \mathrm{0,25} \mathrm{N}$ dan dititrasi dengan $\mathrm{NaOH} 0,1 \mathrm{~N}$ hingga mencapai TAT. Penentuan kadar metoksil dihitung berdasar rumus berikut. Nilai 31 merupakan berat molekul dari gugus metoksil.

Kadar metoksil(\%) $=\frac{\mathrm{mL} \text { titran } \times \mathrm{N} \text { titran } \mathrm{x} 31}{\text { massa } \operatorname{sampel}(\mathrm{mg})}$

\section{Analisis Kadar Galakturonat}

Kadar galakturonat dihitung dari nilai berat ekivalen dan kadar metoksil dengan persamaan sebagai berikut : 


$$
\text { Galakturonat }(\%)=\frac{\mathrm{z} \times 176 \times 100}{\text { massa sampel(mg) }}
$$

Dimana angka 176 adalah berat terendah ekivalen dari asam pektat dan,

$$
\mathrm{z}=\text { miliekivalen }(\mathrm{BE}+\text { metoksil })
$$

Analisis Derajat Esterifikasi

Derajat esterifikasi pektin dapat dihitung dengan :

$$
\mathrm{D} E(\%)=\frac{176 \times \% \text { metoksil } \times 100}{31 \times \text { kadar galakturonat }}
$$

\section{Hasil dan Pembahasan}

Sampel yang digunakan dalam penelitian ini adalah kulit buah pisang raja nangka (Musa paradisiaca Linn.). Buah pisang yang digunakan yaitu buah yang telah matang, memiliki kulit buah berwarna hijau ketika sudah matang, ukuran buah 24-28 cm dengan diameter 3,5-4 cm. Kulit pisang kemudian dikeringkan dan diserbukkan. Proses penyerbukkan ini bertujuan untuk memperbesar luas permukaan bahan untuk kontak dengan pelarut.

\section{Ekstraksi Pektin}

Proses ekstraksi pektin dilakukan menggunakan variasi daya (300 dan 450 W) pada suhu $70{ }^{\circ} \mathrm{C}$ dengan lama waktu ekstraksi $(15,20$, dan 25 menit) dan variasi konsentrasi pelarut asam sitrat $(5,7$ dan 9\%). Hasil rendemen pektin yang diperoleh dirangkum dalam tabel 1.

\begin{tabular}{|c|c|c|c|c|c|}
\hline $\begin{array}{l}\text { Daya } \\
\text { (W) }\end{array}$ & $\begin{array}{l}\text { Konsentrasi } \\
\text { Asam Sitrat (\%) }\end{array}$ & $\begin{array}{l}\text { waktu } \\
\text { ekstraksi } \\
\text { (menit) }\end{array}$ & $\begin{array}{l}\text { Serbuk } \\
\text { Pisang (g) }\end{array}$ & $\begin{array}{l}\text { Ekstrak } \\
\text { kering (g) }\end{array}$ & $\begin{array}{l}\text { Rendemen } \\
(\%)\end{array}$ \\
\hline \multirow{9}{*}{300} & \multirow{3}{*}{5} & 15 & 2,50 & 0,51 & 20,42 \\
\hline & & 20 & 2,50 & 0,52 & 20,91 \\
\hline & & 25 & 2,50 & 0,49 & 19,59 \\
\hline & \multirow{3}{*}{7} & 15 & 2,50 & 0,52 & 20,8 \\
\hline & & 20 & 2,50 & 0,49 & 19,85 \\
\hline & & 25 & 2,50 & 0,45 & 17,99 \\
\hline & \multirow{3}{*}{9} & 15 & 2,50 & 0,53 & 21,18 \\
\hline & & 20 & 2,50 & 0,51 & 20,28 \\
\hline & & 25 & 2,50 & 0,45 & 17,94 \\
\hline \multirow{9}{*}{450} & \multirow{3}{*}{5} & 15 & 2,51 & 0,72 & 28,74 \\
\hline & & 20 & 2,51 & 0,57 & 22,57 \\
\hline & & 25 & 2,51 & 0,48 & 19,04 \\
\hline & \multirow{3}{*}{7} & 15 & 2,51 & 0,48 & 19,04 \\
\hline & & 20 & 2,50 & 0,51 & 20,30 \\
\hline & & 25 & 2,50 & 0,49 & 19,76 \\
\hline & \multirow{3}{*}{9} & 15 & 2,50 & 0,47 & 18,69 \\
\hline & & 20 & 2,50 & 0,56 & 22,51 \\
\hline & & 25 & 2,50 & 0,48 & 19,33 \\
\hline
\end{tabular}

Tabel 1. Rendemen pektin yang diekstraksi dari kulit pisang raja nangka yang diperoleh dalam berbagai kondisi

Berdasar data yang diperoleh dalam Tabel 1, diketahui bahwa pektin dalam kulit pisang dapat diekstraksi menggunakan microwave. Daya microwave dapat meningkatkan rendemen pektin. Rendemen pektin yang paling tinggi $(25,36 \%)$ diperoleh saat kondisi ekstraksi menggunakan pelarut asam sitrat
5\%, lama waktu ekstraksi 5 menit, dan daya microwave $450 \mathrm{~W}$.

Ekstraksi menggunakan microwave ini hanya melibatkan interaksi antara gelombang dan bahan atau larutan reaksi sehingga terjadi pemanasan yang merata dalam sampel. Interaksi molekul dengan medan elektromagnet memberikan transfer 
energi yang cepat untuk pelarut dan matriks pada tanaman, maka memungkin terjadinya disolusi komponen yang hendak diekstrak. Suhu dan daya pada microwave dapat mempercepat rusaknya sel tanaman, sehingga mengakibatkan pektin dapat terdifusi keluar, kemudian larut dalam pelarut, dan meningkatkan rendemen pektin. Oleh karena itu, semakin tinggi daya microwave, semakin tinggi rendemen pektin yang diperoleh dengan lama waktu ekstraksi yang lebih singkat. Akan tetapi ketika lama waktu ekstraksi ditingkatkan, rendemen pektin menurun karena pektin mengalami degradasi. Hal ini sesuai dengan penelitian yang pernah dilakukan oleh Kute dkk., (2015) dan Maran dkk., (2013).

Rendemen pektin terbaik diperoleh saat konsentrasi asam sitrat 5\%. Ketika konsentrasi asam sitrat ditingkatkan, rendemen pektin yang diperoleh semakin menurun. Hal ini sesuai dengan penelitian yang dilakukan oleh Tuhuloula dkk., (2013), menyebutkan bahwa konsentrasi asam yang terlalu tinggi mengakibatkan pektin mengalami hidrolisis lebih lanjut menjadi asam pektat, sehingga rendemen pektin yang dihasilkan menurun.

\section{Analisis Kualitatif Pektin}

Serbuk pektin yang diperoleh kemudian dianalisis kualitatif menggunakan pelarut etanol $96 \%, \mathrm{NaOH}$ $2 \mathrm{~N}$, dan $\mathrm{HCl} 3 \mathrm{~N}$. Berdasar hasil tersebut menunjukkan hasil yang positif pektin karena membentuk endapan ketika ditambah etanol 96\%. Etanol bersifat pendehidrasi sehingga mampu menggumpalkan pektin dari pelarutnya.

Serbuk pektin membentuk gel ketika ditambah $\mathrm{NaOH} 2 \mathrm{~N}$. Hal ini disebabkan karena terjadi penetralan antara 2 koloid yang muatannya berlawanan. Koloid pektin memiliki muatan negatif dan akan menggumpal bila ditambah dengan kation seperti $\mathrm{Na}^{+}$.

Pektin ketika diasamkan dengan $\mathrm{HCl}$ dan didihkan akan menggumpal. Hal tersebut sesuai dengan sifat pektin, dimana penambahan asam kuat dapat menghidrolisis pektin menjadi asam pektat, yang ditandai dengan terbentuknya gumpalan (Daniarsari dan Hidajati, 2010).

\section{Analisis Gugus Fungsi Pektin}

Hasil analisis kualitatif ini kemudian dilanjutkan dengan uji spektrofotometer IR untuk mengetahui gugus fungsi yang terbentuk sehingga dapat memberikan informasi struktur pektin hasil ekstraksi dalam kulit pisang raja nangka. Struktur pektin yang diperoleh dapat dilihat dalam Gambar 1. Pola FTIR pektin ini sesuai dengan penelitian yang telah dilakukan oleh Liew, (2019).

Tabel 2. Spektra FTIR dari gugus fungsi pektin ter-ekstrak.

\begin{tabular}{lll}
\hline \multicolumn{2}{c}{$\begin{array}{c}\text { Bilangan gelombang } \\
\left(\mathbf{c m}^{-1}\right)\end{array}$} & \multicolumn{1}{c}{$\begin{array}{c}\text { Gugus } \\
\text { Fungsi }\end{array}$} \\
\cline { 1 - 2 } $\mathbf{4 5 0} \mathbf{W}$ & $\mathbf{3 0 0} \mathbf{W}$ & \\
\hline 3294,14 & 3288,98 & $\mathrm{O}-\mathrm{H}$ \\
\hline 2919,76 & 2919,28 & $-\mathrm{CH}_{3}$ \\
\hline 1734 & 1734 & $-\mathrm{C}=\mathrm{O}$ ester \\
\hline 1637,09 & 1637,03 & $-\mathrm{COO}$ \\
\hline 1150 & 1148,44 & R-O-R \\
\hline
\end{tabular}

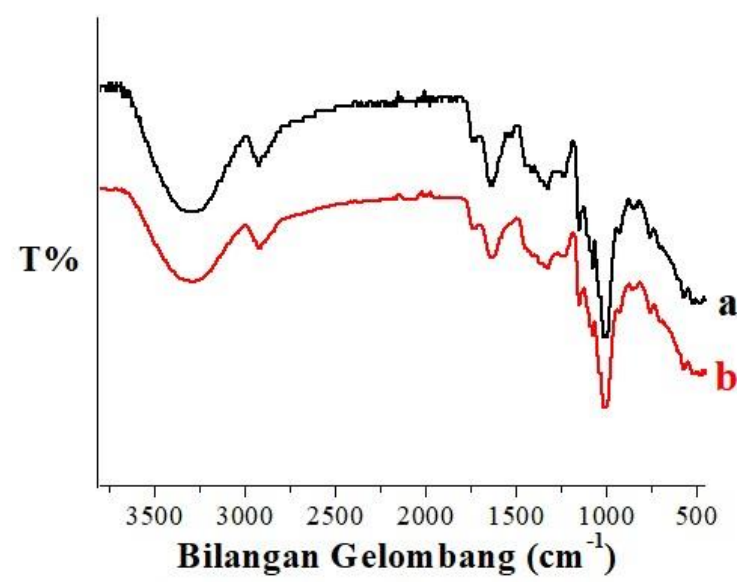

Gambar 1. Spektra FTIR pektin hasil ekstraksi menggunakan metode microwave pada daya $450 \mathrm{~W}$ (a) dan 300 $\mathrm{W}(\mathrm{b})$.

Spektra yang diperoleh antara pektin yang telah diekstraks dengan daya 300 dan $450 \mathrm{~W}$ memiliki spektra yang karakteristik satu sama lain. Berdasar spektra tersebut diketahui adanya gugus hidroksil $(-\mathrm{OH})$ yang terdapat pada bilangan gelombang $3294,14 \mathrm{~cm}^{-1}$. Data yang diperoleh sesuai 
dengan Pavia, dkk., (2009), menyatakan bahwa spektra pektin berkaitan dengan gugus $-\mathrm{OH}$ terletak pada bilangan gelombang 3200-3650 $\mathrm{cm}^{-1}$. Bilangan gelombang 2919,76 $\mathrm{cm}^{-1}$ menunjukkan adanya serapan dari ulur $-\mathrm{CH}_{3}$. Hal tersebut sesuai dengan Pavia, dkk., (2009), dimana spektra gugus metil $\left(-\mathrm{CH}_{3}\right)$ berada pada panjang gelombang $2840-3000 \mathrm{~cm}^{-1}$.

Serapan khas pektin juga dapat diketahui adanya serapan yang terdapat pada daerah bilangan gelombang 1637,09 $\mathrm{cm}^{-1}$. Serapan tersebut menunjukkan serapan gugus $\mathrm{C}=\mathrm{O}$ (karbonil). Data didukung dengan literatur, panjang gelombang karbonil $(\mathrm{C}=\mathrm{O})$ berada pada 1630-1850 cm-1 (Pavia, dkk., 2009). Serapan dari ikatan eter (R-O-R) molekul pektin muncul pada bilangan gelombang $1150 \mathrm{~cm}^{-1}$. Hal ini sesuai dengan literatur bahwa ikatan eter (R-O-R) berada pada kisaran spektrum 1050-1260 $\mathrm{cm}^{-1}$ (Pavia dkk., 2009).

\section{Analisis Kandungan Senyawa Anorganik}

Kandungan mineral suatu bahan dan kemurnian pektin dapat diamati dari kandungan senyawa anorganik yang terdapat didalamnya. Berdasar data pada Tabel 3 menunjukkan bahwa komponen senyawa anorganik yang paling banyak terkandung dalam pektin adalah kalsium (Ca). Hal ini sesuai dengan pernyataan dari
Antika dan Kurniawati, (2017) dan Roikah, dkk., (2016), menyatakan bahwa komponen mineral yang umum terdapat dalam senyawa organik alami adalah kalsium, kalium, besi, dan mangan.

Pektin dalam jaringan tanaman berupa protopektin yang berada dalam bentuk garam kalsium, sehingga tidak larut air. Ikatan kalsium pada protopektin dapat dihidrolisis menggunakan larutan asam. Ion $\mathrm{H}^{+}$pada pelarut asam menggantikan ion kalsium pada protopektin dan mengubah protopektin menjadi pektin yang larut air.

Hasil uji kandungan senyawa anorganik pada penelitian ini juga menunjukkan bahwa semakin lama waktu ekstraksi, konsentrasi $\mathrm{Ca}$ semakin meningkat karena semakin lama bahan kontak dengan larutan asam, maka mineral - mineral alam dari kulit buah pisang yang diekstrak akan semakin banyak yang larut. Lamanya waktu ekstraksi mengakibatkan reaksi hidrolisis protopektin meningkat sehingga komponen kalsium dan larutan ekstrak bertambah. Pada saat proses hidrolisis protopektin menjadi pektin oleh ion hidrogen yang berasal dari asam sitrat, ion kalsium yang terdapat di dalam protopektin akan terlepas, berubah menjadi kalsium sitrat, dan dapat mengendap dalam kondisi asam.

Tabel 3. Kandungan zat anorganik dalam pektin

\begin{tabular}{llll}
\hline \multirow{2}{*}{ Senyawa } & \multicolumn{3}{c}{ Komsentrasi (mg/100g) } \\
\cline { 2 - 4 } & $\begin{array}{c}\text { Lama waktu } \\
\text { ekstraksi } \mathbf{1 5} \text { menit }\end{array}$ & $\begin{array}{c}\text { Lama waktu ekstraksi } \\
\text { 20 menit }\end{array}$ & $\begin{array}{c}\text { Lama waktu ekstraksi } \\
\mathbf{2 5} \text { menit }\end{array}$ \\
\hline $\mathrm{P}$ & 1,5 & 1,6 & 1,5 \\
\hline $\mathrm{K}$ & 36,8 & 29,9 & 29,8 \\
\hline $\mathrm{Ca}$ & 54,5 & 61,6 & 61,9 \\
\hline $\mathrm{Mn}$ & 1,1 & 0,97 & 1,1 \\
\hline $\mathrm{Fe}$ & 2 & 1,5 & 1,7 \\
\hline $\mathrm{Cu}$ & 1,6 & 1,5 & 1,7 \\
\hline $\mathrm{Zn}$ & 0,81 & 0,88 & 0,89 \\
\hline $\mathrm{Sr}$ & 0,57 & 0,55 & 0,79 \\
\hline $\mathrm{Re}$ & 0,8 & 0,5 & 1 \\
\hline
\end{tabular}

\section{Analisis Mutu Pektin}

Mutu pektin yang diamati pada penelitian ini meliputi berat ekivalen, kadar metoksil, dan derajat esterifikasi, yang dapat dilihat dalam Tabel 4. Pada 
tabel tersebut membandingkan mutu pektin hasil ekstraksi dengan metode konvensional dan MAE.

Kadar air pektin dalam penelitian ini tergolong rendah yaitu $3,52 \%$ (metode ekstraksi konvensional), 1,12 (metode MAE daya $300 \mathrm{~W}$ ), dan $1,17 \%$ (metode MAE daya $450 \mathrm{~W}$ ). Kadar air pektin harus rendah agar memiliki umur simpan lama dan mencegah pertumbuhan mikroorganisme yang berpengaruh terhadap kualitas pektin karena adanya produksi enzim pektinase (Ismail, dkk., 2012).
Pektin dengan metode konvensional memiliki kadar air lebih tinggi daripada MAE. Berdasar hal tersebut membuktikan bahwa microwave dapat meningkatkan banyaknya air yang menguap selama proses ekstraksi, dengan demikian mempermudah proses pengeringan dan menghasilkan kadar air rendah. Pada penelitian ini, daya microwave tidak berpengaruh secara signifikan pada kadar air pektin. Hal ini sesuai dengan penelitian yang telah dilakukan oleh Koh, dkk., (2014).

Tabel 4. Mutu pektin kulit pisang raja nangka

\begin{tabular}{lccc}
\hline \multirow{2}{*}{ Analisis } & \multirow{2}{*}{ Konvensional } & \multicolumn{2}{c}{ MAE } \\
\cline { 3 - 4 } & & $\mathbf{3 0 0}$ W & $\mathbf{4 5 0} \mathbf{~ W}$ \\
\hline Yield (\%b/b) & 8,93 & 20,42 & 28,74 \\
\hline Kadar air $(\% \mathrm{~b} / \mathrm{b})$ & 3,52 & 1,12 & 1,17 \\
\hline Berat Ekivalen & 897,16 & 717,73 & 609,39 \\
\hline Kadar Metoksil $(\%)$ & 6,33 & 7,00 & 7,10 \\
\hline Derajat esterifikasi $(\%)$ & 42,84 & 36,67 & 34,39 \\
\hline
\end{tabular}

Berat ekivalen merupakan kandungan gugus asam galakturonat yang tidak teresterifikasi dalam rantai molekul pektin. Asam pektat merupakan senyawa yang komposisi seluruhnya tersusun atas asam poligalakturonat yang tidak mengalami esterifikasi atau tidak memiliki gugus metil ester. Asam pektat memiliki berat molekul 176. Berdasar data pada tabel 4, metode ekstraksi dan daya yang digunakan mempengaruhi berat ekivalen pektin. Semakin tinggi daya yang digunakan, berat ekivalen semakin menurun karena meningkatnya depolimerisasi atau deesterisfikasi pektin, yang menunjukkan bahwa asam pektat meningkat. Berat ekivalen pada penelitian ini sesuai dengan standar IPPA yakni $600-800 \mathrm{~g} / \mathrm{mol}$.

Pektin hasil ekstraksi berbentuk serbuk yang apabila dikontakkan dengan air akan menggumpal dan terhidrasi sebagian. Oleh karena itu, agar pektin dapat larut sempurna maka pada saat penentuan berat ekivalen, pektin dilambabkan menggunakan etanol terlebih dahulu agar terbasahi seluruhnya hingga inti serbuk (Shaha dkk., 2013; Seymour dan Knox, 2000). Pelarut yang digunakan pada saat analisis adalah air bebas $\mathrm{CO}_{2}$ karena adanya gas $\mathrm{CO}_{2}$ dalam air dapat bereaksi dengan $\mathrm{NaOH}$, yang digunakan untuk proses analisis, membentuk garam karbonat sehingga dapat mempengaruhi hasil analisis (Oule dkk., 2013). $\mathrm{NaCl}$ ditambah untuk mempertajam titik akhir titrasi (Shaha dkk., 2013).

Kadar metoksil didefinisikan sebagai banyaknya metanol yang terkandung dalam pektin. Berdasar hasil penelitian ini, pektin yang dihasilkan dikategorikan pektin metoksil rendah karena memiliki nilai kadar metoksil kurang dari 7\% dan nilai derajat esterifikasi kurang dari $50 \%$. Kadar metoksil pada pektin berperan dalam menentukan sifat fungsional larutan pektin dan dapat mempengaruhi struktur dan tekstur gel pektin. Pektin metoksil rendah tidak memiliki kemampuan membentuk gel dengan adanya gula dan asam, tetapi dapat membentuk gel dengan adanya kation bivalen, misalnya $\mathrm{Ca}^{2+}$. 
Pektin metoksil rendah tidak membutuhkan kadar gula yang tinggi untuk pembentukan gel sehingga dapat digunakan sebagai pengental dalam pembuatan minuman rendah kalori, jelly untuk diabetes, dan makanan kesehatan lainnya (Daniarsari dan Hidajati, 2010).

Derajat esterifikasi merupakan persentase gugus karboksil yang teresterifikasi oleh metanol. Hasil penelitian ini sesuai dengan penelitian yang dilakukan oleh Zhang dkk., (2018), dimana ekstraksi menggunakan MAE memiliki derajat esterifikasi yang lebih rendah dibanding ekstraksi konvensional. Daya microwave menyebabkan degradasi gugus metil ester pada pektin menjadi asam karboksilat karena adanya asam. Asam dapat menghidrolisis ikatan hidrogen pada gugus metil ester dari pektin menjadi asam galakturonat. Menurut International Pectin Procedurs Association (IPPA), (2001) dalam Perina I, dkk., (2007) menyatakan bahwa nilai derajat esterifikasi untuk pektin metoksil tinggi memiliki nilai lebih dari 50\%, sedangkan pektin metoksil rendah memiliki nilai $<50 \%$. Pada penelitian ini pektin tergolong metoksil rendah.

\section{Daftar Pustaka}

Antika, S.R., dan Kurniawati, P. 2017. Isolasi Dan Karakterisasi Pektin Dari Kulit Nanas. Prosiding Seminar Nasional Kimia FMIPA Unesa. Universitas Negeri Surabaya, Surabaya.

Bagherian, H., Ashtiani, F.Z., Fouladitajar, A., dan Mohtashamy, M. 2011. Comparisons between Conventional, Microwave- and Ultrasound-Assisted Methods for Extraction of Pectin from Grapefruit. Chemical Engineering and Processing: Process Intensification 50(11-12), 1237-1243.

Chaharbaghi, E., Khodaiyan, F., dan Hosseini, S.S. 2017. Optimization of Pectin Extraction from Pistachio

\section{Kesimpulan}

Pektin dapat diekstraksi dari kulit pisang raja nangka menggunakan metode Microwave Assisted Extraction (MAE) dengan pelarut asam sitrat. Hasil rendemen pektin, yang diperoleh pada saat proses ekstraksi menggunakan microwave, lebih tinggi dibandingkan ekstraksi menggunakan pemanasan langsung. Rendemen pektin tertinggi diperoleh saat menggunakan pelarut asam sitrat dengan konsentrasi 5\%, lama waktu ekstraksi 15 menit, dan daya microwave 450 W. Kadar air, berat ekivalen, kadar metoksil, dan derajat esterifikasi yang diperoleh adalah sebesar 1,17\%; 609,39; 7,10\%; dan $34,39 \%$. Oleh karena itu, dapat disimpulkan bahwa pektin yang diperoleh pada penelitian ini sudah sesuai dengan standar IPPA (International Pectin Procedurs Association) dan memiliki potensial sebagai pengental dalam industri pangan.

\section{Ucapan Terima Kasih}

Penulis mengucapkan terimakasih kepada DRPM Kemenristekdikti yang telah mendanai penelitian ini melalui Hibah Penelitian Dosen Pemula Tahun 2019.

Green Hull as a New Source. Carbohydrate Polymers. 173, 107113.

Chan, Siew Yin, dan Choo, Wee-Sim. 2013. Effect of Extraction Conditions on the Yield and Chemical Properties of Pectin from Cocoa Husks. Food Chemistry, 141(4), 3752-3758

Daniarsari, I., dan Hidajati, N. 2005. The Influence of the Extraction Temperature on the Rendement and Pectin Methoxyl Contents of Waterhyacinth (Eichornia Crassipes (Mart) Solms). Indonesian Journal of Chemistry, 5(3), 232-235.

Devianti, V.A., Chrisnandari, R.D., dan Darmawan, R. 2019. Pengaruh Metode Pemanasan Langsung dan 
Gelombang Mikro terhadap Ekstraksi pektin dalam Kulit Pisang Raja Nangka. Prosiding Seminar Nasional Perhipba. Universitas Pancasila, Jakarta.

Dranca, F., dan Oroian, M. 2018. Extraction, Purification and Characterization of Pectin from Alternative Sources with Potential Technological Applications. Food Research International, 113, 327350.

Gazala, K., Masoodi, F.A., Masarat, H.D., Rayees, B., dan Shoib, M.W. 2017. Extraction and Characterisation of Pectin from Two Apple Juice Concentrate Processing Plants. International Food Research Journal, 24(2), 594-599.

Ismail, N.S.M., Ramli, N., Hani, N.M., dan Meon, Z. 2012. Extraction and Characterization of Pectin from Dragon Fruit(Hylocereus Polyrhizus) Using Various Extraction Conditions. Sains Malaysiana, 41(1), 41-45.

Koh, P.C., Leong, C.M., dan Noranizan, M.A. 2014. Microwave - assisted Extraction of Pectin from Jackfruit Rinds using Different Power Levels. International Food Research Journal, 21(5), 2091-2097.

Kute, A., Mohapatra, D., Babu, B., dan Sawant, B.P. 2015. Optimization of Microwave Assisted Extraction of Pectin from Orange Peel Using Response Surface Methodology. Journal of Food Research and Technology, 3(2), 62-70.

Liew, S.Q., Teoh, W.H., Yusof, R., dan Ngoh, G.C. 2019. Comparisons of Process Intensifying Methods in The Extraction of Pectin from Pomelo Peel. Chemical Engineering and Processing - Process Intensification, 143.

Maran, J.P., Sivakumar, V., Thirugnanasambandham, K., dan Sridhar, R. 2013. Optimization of Microwave Assisted Extraction of Pectin from Orange Peel.
Carbohydrate Polymers, 97(2), 703709.

Methacanon, P., Krongsin, J., dan Gamonpilas, C. 2013. Pomelo (Citrus Maxima) Pectin: Effects of Extraction Parameters Andits Properties. Food Hydrocolloids, 35, 383-391.

Oule, K.M., Dickman, M., Arul, J. 2013. Properties of Orange Juice with Supercritical Carbon Dioxide Treatment. International Journal of Food Properties. 16(8), 1693-1710.

Pavia, D.L., Gary, M.L., George, S.K. 2009. Introduction to Spectroscopy edition IV. Washington: Department of Chemistry. Western Washington, Bellingham.

Perina I., Satiruiani, Soetaredjo, F.E., dan Hindarso, H. 2007. Ekstraksi Pektin dari Berbagai Macam Kulit Jeruk. Jurnal Ilmiah Widya Teknik, 6(1), 110.

Pusat Data dan Sistem Informasi Pertanian, 2016, Outlook Pisang : Komoditas Pertanian Sub Sektor Hortikultura. Kementerian Pertanian. ISSN:1907-1507.

Rahmati, S., Abdullah, A., dan Oon Lee Kang. 2019. Effects of Different Microwave Intensity on the Extraction Yield and Physicochemical Properties of Pectin from Dragon Fruit (Hylocereus Polyrhizus) Peels. Bioactive Carbohydrates and Dietary Fibre, 18,100-186

Rodsamran, P., dan Sothornvit, R. 2019. Microwave Heating Extraction of Pectin from Lime Peel: Characterization and Properties Compared with the Conventional Heating Method. Food Chemistry, 278, 364-372.

Roikah, S., Rengga, W.D.P., Latifah, dan Kusumastuti, E. 2016. Ekstraksi Dan Karakterisasi Pektin Dari Belimbing Wuluh (Averrhoa Bilimbi,L). Jurnal Bahan Alam Terbarukan, 5(1), 2936.

Sandarani, MDJC. 2017. "A Review: 
Different Extraction Techniques of Pectin." Journal of Pharmacognosy \& Natural Products, 3(3): 1-5.

Seymour, G.B., dan Knox, J.P. 2000. Pectins and Their Manipulation. USA dan Canada : Blackwell Publishing.

Shaha, R.K., Punichelvana, Y. N. A. P., dan Afandi, A. 2013. Optimized Extraction Condition and Characterization of Pectin from Kaffir Lime (Citrus Hystrix). Research Journal of Agriculture and Forestry Sciences, 1(2), 1-11.

Swamy, G.J., dan Muthukumarappan, K. 2017. Optimization of Continuous and Intermittent Microwave Extraction of Pectin from Banana Peels. Food Chemistry, 220, 108114.

Tuhuloula, A., Budiyarti, L., dan Fitriana,
E.N. 2013. Karakterisasi Pektin dengan Memanfaatkan Limbah Kulit Pisang menggunakan Metode Ekstraksi. Jurnal Konversi, 2(1): 2127.

Woo, K.K., Chong, Y.Y., Li Hiong, S.K., dan Tang, P.Y. 2010. Pectin Extraction and Characterization from Red Dragon Fruit (Hylocereus Polyrhizus): A Preliminary Study. Journal of Biological Sciences, 10(7), 631-636.

Zhang, M., Zeng, G., Pan, Y., dan Na Qi. 2018. Difference Research of Pectins Extracted from Tobacco Waste by Heat Reflux Extraction and Microwave-Assisted Extraction. Biocatalysis and Agricultural Biotechnology, 15, 359-363. 